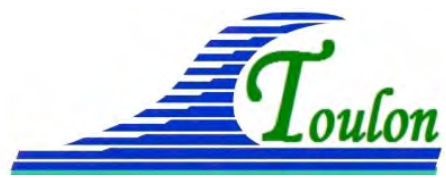

XIV èmes Journées Nationales Génie Côtier - Génie Civil Toulon, 29 juin au $1^{\text {er }}$ juillet 2016

DOI:10.5150/jngcgc.2016.040 (C) Editions Paralia CFL disponible en ligne - http://www.paralia.fr - available online

\title{
SAR-based techniques to extract bathymetric features
}

\author{
Marc CLOAREC ${ }^{1}$, Jean DUBRANNA ${ }^{1}$, Thierry RANCHIN ${ }^{1}$
}

1. O.I.E. Centre Observation, Impacts, Energie, MINES ParisTech, PSL - Research University Rue Claude Daunesse, CS 10207, 06904 Sophia Antipolis cedex, France. \{marc.cloarec; jean.dubranna; thierry.ranchin\}@mines-paristech.fr

\begin{abstract}
:
This paper presents a survey of Synthetic Aperture Radar-based techniques that are used to extract bathymetric features or create bathymetric maps. With standard techniques, realization of a bathymetric map is currently very expensive. Indeed, the best results are achieved by onboard multi-beam sonars but measurement campaigns are very expensive and time-consuming especially for large coverage or remote areas.

SAR-based imaging methods can help to reduce the costs and improve the coverage of bathymetric data. To achieve the needs of the marine renewable energy sector, two main approaches to perform the extraction of bathymetric information exist: current-based method and wave-based method. For each of them, we will discuss their applicability and their quality.
\end{abstract}

Keywords: Bathymetry, Synthetic Aperture Radar, Bottom topography, Wave-based model, Current-based model, Review.

\section{Introduction}

Bathymetry is the measurement of underwater topography. It is of great importance for a large majority of ocean-related issues.

Currently, bathymetric maps are typically achieved from onboard echo-sounders measurements, synchronized with GPS and inertial sensors. Bathymetric campaigns are highly time-consuming, costly and the measurements may need to be regularly updated in the case of time-varying bathymetry, typically in shallow sandy environments.

Remote sensing methods to retrieve bathymetry are giving usable results for industrial needs in installations of offshore technologies. Near coastal regions, optical sensors can be used to retrieve bathymetry from water color gradients. They are suitable for depths down to $20 \mathrm{~m}$, and depend a lot on water turbidity (PLESKACHEVSKY \& LEHNER, 2011).

The use of Synthetic Aperture Radar (SAR) imaging is an alternate solution for measuring water depth down to about $100 \mathrm{~m}$. The principle is based on the interference between the electromagnetic microwaves signal sent by the satellite with the sea surface roughness that is sensitive to bathymetric features. There are two main categories of approaches to process SAR-based images in order to extract bathymetry: current-based and wave-based approaches. 


\section{Discovering SAR image}

The SAR system is a form of radar emitting and receiving an electromagnetic microwave and processing it by electronics to produce an image. The signal backscattered from the emission of successive high frequency modulated pulses of shortwave radiation is received by the SAR antenna. The image produced by SAR is related with the intensity of this backscattered signal. SAR is a side-looking system (Figure 1) mounted on a platform flying parallel to the flight direction, with the nadir directly beneath the platform. Range refers to the across-track direction and azimuth to the along-track direction. The incidence angle is the angle between the radar beam and ground surface. The slant range distance is the distance between the radar and any ground target.

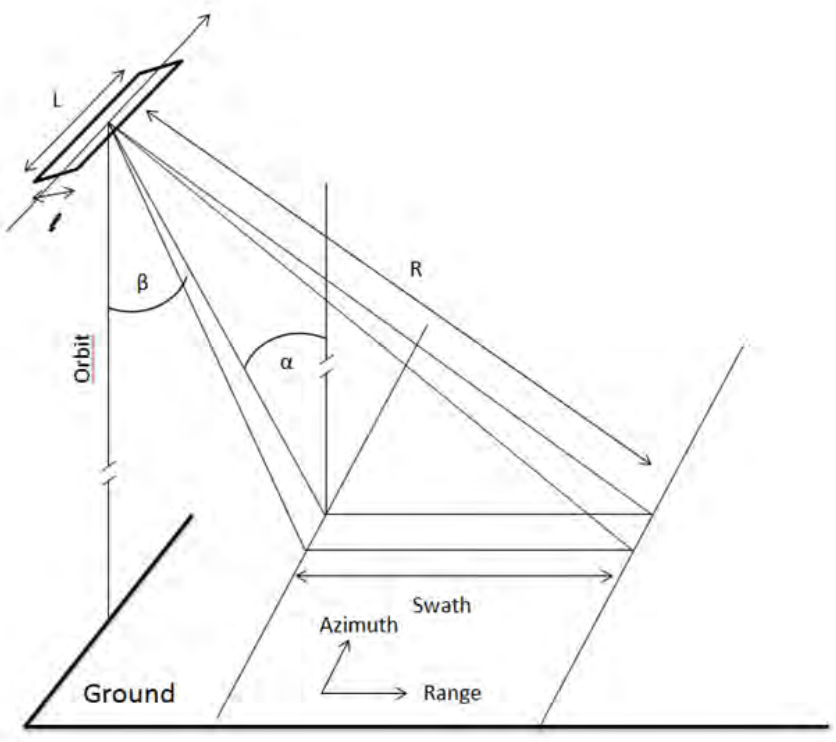

Figure 1. SAR viewing geometry where is the incidence angle, is the look angle, $R$ is the slant range $L$ and $l$ are respectively the length and width of the antenna.

SAR images of the sea surface are formed by a complex processing. The signal emitted by SAR is backscattered by ground features (targets). Each target is defined by its Normalized Radar Cross Section and the integration of each one of them in an image pixel contributes to its intensity. These targets have length scales ( ) matching the wavelength of the emitted signal ( ) combined with an influence of the incidence angle

(Bragg's conditions):

$$
\lambda_{B}=\frac{\lambda}{2 \sin \alpha}
$$




\section{XIV èmes Journées Nationales Génie Côtier - Génie Civil \\ Toulon, 29 juin au $1^{\text {er }}$ juillet 2016}

Capillary waves satisfying Bragg's condition are called Bragg-waves. They generate constructive interferences with microwave pulses emitted from SAR and are the only one contributing to the intensity of the backscattered signal. A slick ocean surface with no Bragg-waves will be transparent to SAR and have no signature on a SAR image. Bathymetry-dependent phenomena are able to affect the characteristics of Bragg-waves at the surface and influence accordingly the SAR image.

\section{Current based methods}

\subsection{Discovery of SAR bathymetry}

The first civil spaceborne SAR was launched in 1978 onboard the satellite Seasat. The images it delivered showed signs of bathymetric features. ALPERS and HENNINGS (1984) developed a breakthrough, although simplified, method to retrieve bathymetric features from SAR images. Their approach has become the basics for any existing current-based bathymetric reconstruction model. The imaging process is the first important aspect of their approach. Their early work on a large amount of images allowed them to state that underwater topographic features like sandbanks or shoals become visible on radar images under the following conditions: the incidence angle of the emitted signal should be between $20^{\circ}$ and $70^{\circ}$, wind conditions should be moderate ( $3-10 \mathrm{~m} / \mathrm{s}$ ) and surface currents should be strong $(>0.5 \mathrm{~m} / \mathrm{s})$. These conditions are the bases of Alpers and Hennings' three-step mechanism theory, under the following hypothesis:

i) Interaction between tidal flow and bottom topography produces variations in the current velocity at the sea surface.

ii) Variations in the surface current velocity give rise to modulations in the wind generated spectrum of water waves.

iii)Modulation in the surface roughness causes variations in the radar backscatter and shows up as amplitude modulation in radar images.

The first step pertains to the interaction between bottom topography and surface currents. It is defined by the hydrodynamic equations in shallow waters and laws of mass conservation. For SAR imagery, the flow is assumed to be incompressible and laminar, time-independent and that the vertical current is negligible. ALPERS and HENNINGS (1984) used Equation 2 relating normal and parallel components of the surface current respectively $U_{\perp}$ and $U_{/ /}$and a depth profile along a line normal to a ridge $d\left(x_{\perp}\right)$

$U_{\perp}\left(x_{\perp}\right) d\left(x_{\perp}\right)=$ const

$U_{/ /}=$const

The second step is the Action Balance Equation (ABE), linking the variations of the sea surface current with the characteristics of the Bragg-waves that are imaged by the SAR. 
Equation 3 describes the variation of the spectral energy density of short waves in a slowly varying current field.

$\left(\frac{\partial}{\partial t}+\vec{x}^{\prime} \frac{\partial}{\partial \vec{x}}+\vec{k}^{\prime} \frac{\partial}{\partial \vec{k}}\right) n(\vec{x}, \vec{k}, t)=s(\vec{x}, \vec{k}, t)$

where $n$ is the action spectrum, $\vec{x}$ is the space variable, $\vec{k}$ is the wave number. The linear approximation (neglecting advection terms) of the source $s$ is given by:

$s(\vec{x}, \vec{k}, t)=-\mu(\vec{k})\left[n(\vec{x}, \vec{k}, t)-n_{0}(\vec{k})\right]$

where $\mu$ is the relaxation rate representing a measure of the response time of the wave spectrum to current variations. The radar cross-section modulation is proportional to the product of the relaxation rate and the gradient of the surface current velocity, which is proportional to the slope of the water depth divided by the square of the depth. No measurement of the relaxation rate exists in the ocean. Therefore, it is chosen based on theory and cannot account for steep slopes in the topography. ABE, after neglecting the second order terms and substituting in (3) gives

$\frac{\partial n(\vec{x}, \vec{k}, t)}{\partial t}+\left[\vec{c}_{g}(\vec{k})+\vec{u}(\vec{x}, t)\right] \frac{\partial n(\vec{x}, \vec{k}, t)}{\partial \vec{x}}-\vec{k} \frac{\partial \vec{u}(\vec{x}, t)}{\partial \vec{x}} \cdot \frac{\partial n(\vec{x}, \vec{k}, t)}{\partial \vec{k}}=-\mu(\vec{k})\left[n(\vec{x}, \vec{k}, t)-n_{0}(\vec{k})\right]$

According to VOGELZANG (1989), neglecting the advection rate in the ABE as in Alpers and Hennings' linear approach was a significant source of error. He consequently considered two different source functions to solve the ABE. He used ALPERS and HENNINGS (1978) linear source function and another one modeled as a function of wavenumber and wind speed variations. His conclusions were that advection time was important to solve the ABE numerically. Second order terms are of little importance. This method depends on the type of microwaves sent by the SAR. VOGELZANG (1989) found that the first linear theory could be improved considering Bragg's scattering model.

Finally the third step focusses on the response of the SAR to the surface roughness related with Bragg-waves. This response is determined by the action of surface currents on short surface waves.

\subsection{Bathymetric Assessment System (BAS)}

To our knowledge, the BAS is the first and currently the only commercial system that retrieves bathymetric data from SAR images (CALKOEN et al., 2001). It is based on two principles:

a) An imaging model able to simulate a SAR image from depth maps and tidal data,

b) A data assimilation inversion scheme.

The BAS needs one or more SAR images and reference depth measurements to produce a depth map. These reference points are used to calibrate the imaging system and generate a first-guess depth map to initiate the process of data assimilation inversion. 


\section{XIV èmes Journées Nationales Génie Côtier - Génie Civil \\ Toulon, 29 juin au $1^{\text {er }}$ juillet 2016}

A simulated SAR image calculated from first guess depth maps is then created and compared to a real SAR image. The differences between them is used to simulate a second image. This process is iterated until it converges to a final solution.

Examples of performance have shown in the Plaatgat area, a tidal inlet between the Dutch isles Ameland and Schiermonnikoog in Nederland. The bias error is of the order of $2 \mathrm{~cm}$ and the RMS and absolute error are of $20 \mathrm{~cm}$. The error is smaller than $50 \mathrm{~cm}$ in 95\% of cases (CALKOEN et al., 2001).

The first and major limit of this first BAS version is that the inversion program is $1 \mathrm{D}$, and it is only suitable for simple bottom topographies. BMT ARGOSS has developed a 2D version of BAS (DE VALK, WENSINK, 2002) with two dimensional models of tidal currents and wave current interactions.

\subsection{Volterra Series Expansions (VSE)}

INGLADA and GARELLO (2002) introduced a new model using VSE as a tool for accessing a relationship between the current and the SAR image pixel. This method consists in rewriting the classical modeling of the SAR underwater bottom topography imaging mechanism using a Volterra series expansion. The theory of VSE can be applied to solve the previously seen ABE under different hypothesis.

Numerical models already exist to resolve the ABE and compute the surface roughness from which the backscattering coefficient is inferred. Possible nonlinear processes of the mechanism make a function between the current and the SAR image pixel uneasy to find, even its existence is not ensured. It is possible to quantify the effects of nonlinearities associated with the intensity in the image. VSE allow the user to associate energy with each term. If the higher order terms have a low energy, the model can be inverted. Those nonlinearities can be localized in the spectral dimension.

Variations of surface currents are calculated from modulations in SAR images. Then these variations are used as input to inverse the continuity equations in order to retrieve bathymetry.

Parameters have to be set to derive variations of surface currents in order for this method to work. They are: coefficients representing contribution of backscattering targets, the parameters of the selected source function (relaxation rate, wind conditions, etc.) (Equation 4) and boundary conditions to integrate the shallow water equations. Those cannot be retrieved from the SAR: this method needs exterior sources. The model can take into account advection and relaxation rates and velocity bunching and simulate intensity of a SAR image corresponding to certain bathymetries. The use of VSE allows taking into account the parameters that were oversimplified in the earlier methods. The VSE method uses the algorithm illustrated in Fig. 2. 


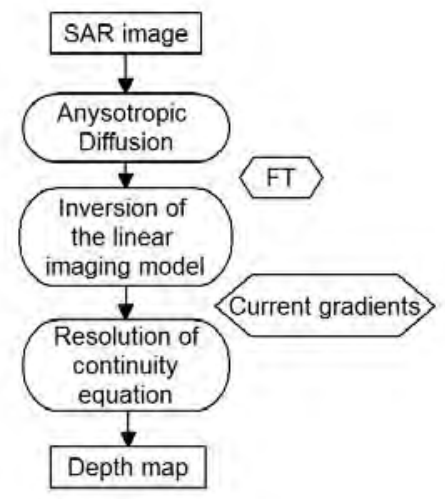

Figure 2. Representation of the algorithm used by (INGLADA \& GARELLO, 2002) to retrieve bathymetric features using Volterra Series Expansion from a SAR image.

Anisotropic diffusion is used to smooth the image, enhance bathymetric features and reduce the noise. The inversion step yields the gradient of surface current. Finally, depth is retrieved by the solving continuity equations.

The equations proposed by Inglada and Garello (INGLADA \& GARELLO, 2000 \& 2002) allow to study nonlinearities in the image processing. It also gives a general expression for the inversion mechanism. Using this algorithm avoids the use of iterative data assimilation techniques and is only based on the physical knowledge about the imaging mechanism.

\section{Wave-based method}

\subsection{Theory of swell waves}

Two main processes are influencing the propagation of long-period sea surface waves over variable bathymetry. First, refraction makes the wave crests bend according to the water depth variations, driving them to become perpendicular to the bathymetric gradient, or until the wave breaks. Secondly, shoaling makes the height of swell waves increase and their wavelength decrease as they travel from deep to shallow water. In addition, steep bathymetric gradients can induce the reflection of part of the wave energy. Strong surface currents can have the same refraction effect on swell waves than bathymetric variations due to phase velocity changing i.e. the speed at which a crest moves.

Results of experimental surveys (PLESKACHEVSKY et al., 2011) have shown that swell wavelength imaged by SAR represent an unbiased estimate of its true wavelength which means that a calculation of this wavelength is possible. 


\section{XIV èmes Journées Nationales Génie Côtier - Génie Civil \\ Toulon, 29 juin au $1^{\text {er }}$ juillet 2016}

\subsubsection{Linear approach}

Airy's wave theory, also referred to as linear wave theory, describes swell propagation in a linear version where bathymetry can be retrieved from the values of wavelength and wave period. Since swell wavelengths are larger than $1 \mathrm{~m}$, surface tension and viscosity will be neglected. Therefore swell propagation gives the dispersion relation which can be generalized in shallow water by

$\omega=\sqrt{g k \tanh k h}+\vec{k} \cdot \vec{u}_{c}$

where $\mathrm{h}$ is the depth $\omega$ is the angular frequency, $\mathrm{k}$ the wavenumber, $\mathrm{g}$ is the acceleration due to gravity and $\vec{k} \cdot \vec{u}_{c}$ is the Doppler frequency indicating that a near-surface current would lead to a frequency shift.

\subsubsection{Nonlinear aspects}

Depending on the application requirements, the linear theory can become insufficient (FLAMPOURIS S. et al., 2009). For a more accurate description of swell and greater specific applications, it has become necessary to develop nonlinear wave theories in addition of those already existing.

These nonlinear theories describe mass transport that had been neglected so far. Stokes first order theory is linear, wave are symmetrical about the still-water level whereas higher orders define asymmetrical waves with respect to the horizontal plane.

Data necessary for higher order theories include parameters that are not easily accessible with a great precision. The height of a wave as well as its period are very important parameters. Therefore a lack of precision in those can lead to inaccuracies concerning equation of high order. As a result, greater inaccuracies in the final product can appear using nonlinear theories than if nonlinear processes had been neglected. This theory is not always justified if data are not sufficiently accurate and linear dispersion relation is sufficient.

\subsection{Image processing method}

Using swell propagation to measure bathymetry is relatively new compared to ALPERS and HENNINGS's early method (1984).

PLESKACHEVSKY and LEHNER (2011) method consists in using the Fast Fourier Transform (FFT) in order to track one wave ray and determine along the way its direction and wavelength. First-checking is applied to evaluate the validity of the scene, to obtain the threshold for filtering of wavelengths and directions. Then, the peak period is estimated: this determination is based on a combination of first-guess for the depths and analysis of reference-tracks. A sub-image is created to capture several waves in order to compute the FFT and recover the wavelength and direction of the wave tracked. It is necessary for the sub-image to capture a sufficient number of waves in order to 
compute the FFT accurately. This FFT box is moved along the wave path from its starting point down to the shoreline as shown in the principle depicted in Figure 3.

Wind streaks and wind sea patterns are removed from the spectra by filtering out wavelengths out of the 80 to 300 meters. To be sure that the wave followed is the right one from one sub-image to another, the swell propagation direction should not deviate from more than $+/-15^{\circ}$.

To retrieve water depth, the linear dispersion relation for ocean gravity waves is used. The solution of the dispersion relation leads to water depth $\mathrm{d}$ :

$d\left(\lambda_{P}, \omega_{P}\right)=\frac{\lambda_{P}}{2 \pi} \arctan h\left(\frac{\omega_{P}^{2} \lambda_{P}}{2 \pi g}\right)$

where $\omega_{P}$ is the angular wave peak frequency $\left(\omega_{P}=2 \pi / T_{P}, T_{P}\right.$ is the peak period).

If surface currents occur, the dispersion relation, is modified accordingly:

$\omega_{j}^{2}=g k_{j} \tanh \left(k_{j} d\right)+U . k_{j}$

where $U$ is the vector component of the surface currents along $j$-wave propagation direction.
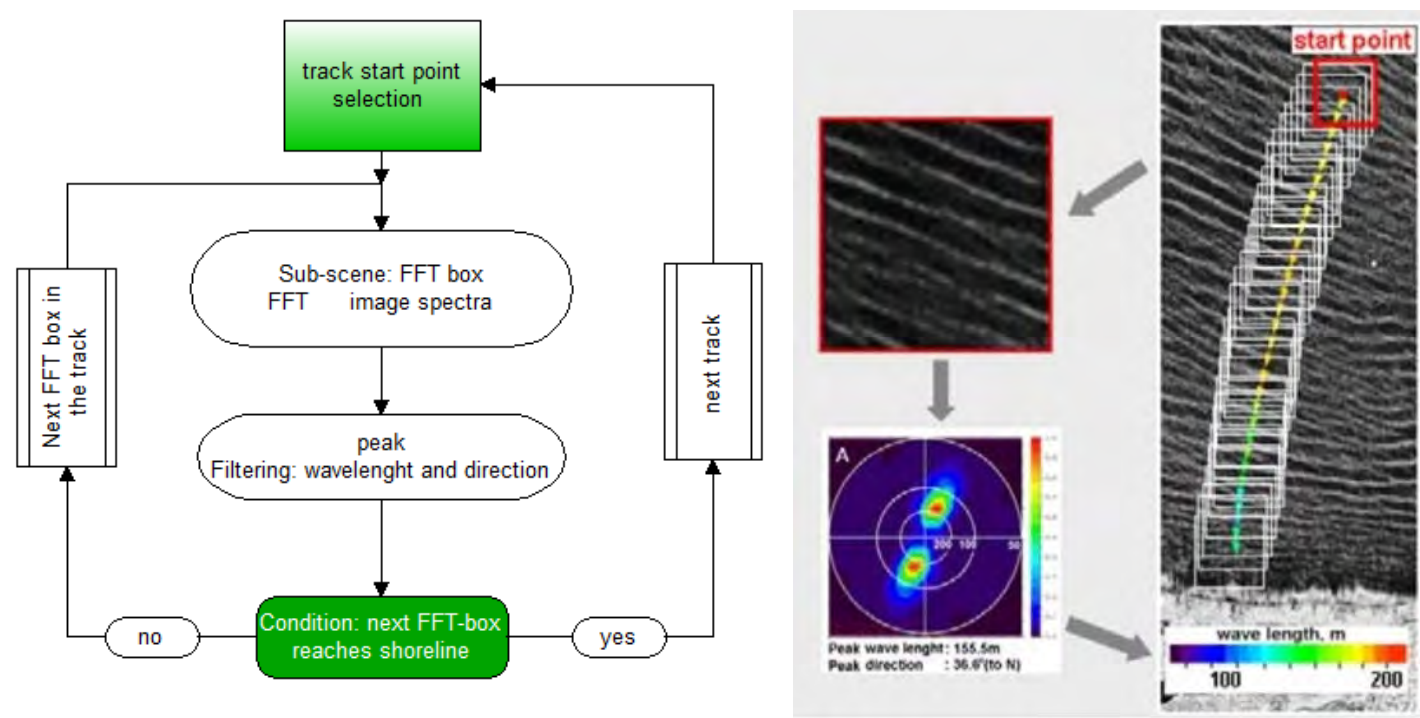

Figure 3. Algorithm for tracking wave rays left and example of Pleskachevsky and Lehner (2011)'s method to track one wave ray right (PLESKACHEVSKY \& LEHNER, 2011).

This method can be used where long swell waves are travelling toward an open coast, is applicable for wave height greater than $0.5 \mathrm{~m}$ and wavelength greater than $80 \mathrm{~m}$.

\section{Conclusions}

In the domain of bathymetric measurements, SAR imaging is currently an exploratory alternative for water depths ranging between about 10 and $100 \mathrm{~m}$. Two methods exist to 


\section{XIV $V^{\text {èmes }}$ Journées Nationales Génie Côtier - Génie Civil \\ Toulon, 29 juin au $1^{\text {er }}$ juillet 2016}

retrieve bathymetric features from SAR images. One of them is using the bathymetryinduced variations of surface currents and the other one of sea surface gravity waves. Both are based on the influence that currents and waves have on the surface ripples (Bragg-waves) that are interfering with the signal emitted by SAR. They have limitations too. For the current approach, bathymetric features appear under conditions with currents higher than about $0.5 \mathrm{~m} / \mathrm{s}$, wind conditions between 3 and $10 \mathrm{~m} / \mathrm{s}$ and an angle of the emitted signal between 20 and $70^{\circ}$. For the wave approach, the swell needs to have a wavelength longer than about $80 \mathrm{~m}$ when propagating over shallow waters in order to be influenced by the bottom topography. Nevertheless, there is no synergy of these two approaches. In fact, both methods work independently from one another. In future work, we will assess further the level of complementarity of the two approaches, implementing both and comparing their results.

\section{References}

ALPERS W., HENNINGS I. (1984). A Theory of the Imaging Mechanism of Underwater Bottom Topography by Real and Synthetic Aperture Radar. Journal of Geophysical Research: Oceans, Vol. 89, pp 10529-10546. http://dx.doi.org/10.1029/JC089iC06p10529

CALKOEN C.J., HESSELMANS G.H.F.M., WESINK G.J., VOGELZANG J. (2001). The Bathymetry Assessment System. Efficient depth mapping in shallow seas using radar images. International Journal of Remote Sensing, Vol. 22(15), pp 2973-2998. http://dx.doi.org/10.1080/01431160116928

DE VALK C.F., WENSINK G.J. (2002). Measuring the bathymetry of shallow seas using radar imagery from satellite and aircraft. In Proceedings of the Offshore Technology Conference, Houston, paper 14276. http://dx.doi.org/10.4043/14276-ms

FLAMPOURIS S., SEEMAN J., ZIEMER F. (2009). Sharing our Experience Using Wave Theories Inversion for the Determination of the Local Depth. Proceedings of OceanSAR 2009, Herrsching, Germany, Sept. 7-11. http://dx.doi.org/10.1109/oceanse.2009.5278331

INGLADA J., GARELLO R. (2000). Underwater Bottom Topography Estimation from SAR Images by Regularization of the Inverse Imaging Mechanism. Geoscience and Remote Sensing Symposium. Proceedings. IGARSS. IEEE International, http://dx.doi.org/10.1109//GARSS.2000.858143

INGLADA J., GARELLO R. (2002). On Rewriting the Imaging Mechanism of Underwater Bottom Topography by Synthetic Aperture Radar as a Volterra Series Expansion. IEEE Journal of Oceanic Engineering, Vol. 27, pp 665-74 http://dx.doi.org/10.1109/JOE.2002.1040949

PLESKACHEVSKY A., LEHNER S. (2011). Estimation of Underwater Topography Using Satellite High Resolution Synthetic Aperture Radar Data. 4. TerraSAR-X Science Team Meeting. 
Thème 3 - Instrumentation, mesures, imagerie et télédétection

VOGELZANG J. (1989). The mapping of bottom topography with imaging radar. A comparison of the hydrodynamic modulation in some existing models. International Journal of Remote Sensing, Vol. 10(9), pp 1503-1518. http://dx.doi.org/10.1080/01431168908903986 